\title{
Formation of periodic layered structure during hot-dip galvanizing in
}

\author{
Al-Zn-Mg bath \\ Linjie Gao $^{\text {a, b }}$, Zhi Li ${ }^{\text {a, b, c* }}$, Xiaowei Kuang ${ }^{\text {a, b }}$, Fucheng Yin ${ }^{\text {a, b }}$, Hong Ji ${ }^{\mathrm{d}}$ \\ ${ }^{a}$ Key Laboratory of Materials Design and Preparation Technology of Hunan Province, \\ Xiangtan University, Xiangtan, Hunan, 411105, P.R. China. \\ ${ }^{\mathrm{b}}$ School of Materials Science and Engineering, Xiangtan University, Xiangtan, Hunan, \\ 411105, P.R. China. \\ ${ }^{c}$ National Defense Key Laboratory of Key Film Materials \& Application for Equipment, \\ Xiangtan University, Xiangtan, Hunan, 411105, P.R. China. \\ ${ }^{\mathrm{d}}$ Electrical Work District, Energy Control Center, Shaanxi Longmen Iron \& Steel Group \\ CO. LTD, Hancheng, Shaanxi, 715400, P.R. China
}

*Corresponding author: Zhi Li; Tel: + 860731 58292213; E-mail address: lizhiclsj@163.com

\begin{abstract}
This study investigated the effect of $\mathrm{Al}$ and $\mathrm{Mg}$ content and immersion time on the formation of periodic layered structure during hot-dip galvanizing in $\mathrm{Al}-\mathrm{Zn}-\mathrm{Mg}$ bath. The steel substrates were immersed in $\mathrm{Al}-\mathrm{Zn}$ bath for $10 \mathrm{~s}$ to $120 \mathrm{~s}$, with five levels of $\mathrm{Al}$ content in the range of 15 to $55 \mathrm{wt} . \%$, and four levels of $\mathrm{Mg}$ additions, in the range of 0.5 to $3.0 \mathrm{wt} . \%$. The microstructure and constituent phases of the periodic layered structure were characterized by optical microscopy, scanning electron microscopy, energy dispersive spectroscopy, X-ray diffraction and X-ray photoelectron spectroscopy. The coating with periodic layered structure contains a thin light gray $\mathrm{Fe}_{2} \mathrm{Al}_{5} \mathrm{Zn}_{\mathrm{x}}$ layer near substrate and outer periodic layered structure.
\end{abstract} The periodic layered structure consists of alternating light gray layer $\left(\mathrm{FeAl}_{3} \mathrm{Zn}_{\mathrm{x}}\right)$ and black 
gray layer ( $\mathrm{Al}$ dendrites and $\mathrm{Zn}$-rich interdendritic regions). The formation of periodic layered structure requires an incubation period $t_{1}$, while if the immersion time is over $t_{2}$, the periodic layered structure is destroyed. In addition, $\mathrm{t}_{1}$ and $\mathrm{t}_{2}$ varies with the $\mathrm{Al}$ content and $\mathrm{Mg}$ addition.

Keywords: Hot-dip galvanizing; Al-Zn-Mg coating; Periodic layered structure; Immersion time 


\section{Introduction}

Al-Zn coatings are predominantly used to improve the corrosion resistance of steel, due to the sacrificing protection from $\mathrm{Zn}$ and the long lasting physical barrier from aluminum oxide [1]. In recent years, a large amount of studies have been focused on the investigation of Al-Zn coatings by alloying a number of elements to acquire improved corrosion resistant performance [2-5]. Magnesium is one of the most popular elements added into the Al-Zn bath because of the excellent performance of Al-Zn-Mg coatings, such as corrosion resistance, wear resistance, welding characteristic [5-6]. The published reports in Al- $\mathrm{Zn}-\mathrm{Mg}$ coatings are mainly focused on low Al content [5-9], while few studies are focused on Al-Zn-Mg coatings with high Al content. Recently, as Wang [10] analyzed the microstructure and corrosion behavior of $45 \mathrm{Al}-\mathrm{Zn}-\mathrm{Mg}$ coatings, he found a typical periodic layered structure in some samples. The results of salt spraying testing showed that the corrosion resistance of the coating with periodic layered structure was excellent. This interesting discovery led the authors to investigate the $\mathrm{Al}-\mathrm{Zn}$ coatings with $\mathrm{Mg}$ additions furtherly.

The periodic layered structure was found for the first time by Liesegang in liquid-gelatine systems [11]. The formation of periodic layered structure in solids was firstly discovered by the research group of Osinski et al. in 1982 [12]. This discovery indicated that such periodic layered structure consists of a periodic sequence of layers which grow parallel to the substrate. After that, various reports have been published that are focused on the formation of such periodic layered structure in solid-solid reaction systems, such as $\mathrm{NiCoFe} / \mathrm{Mg}$ [13], $\mathrm{SiO}_{2} / \mathrm{Mg}$ [14], $\mathrm{Co}_{2} \mathrm{Si} / \mathrm{Zn}$ [15], $\mathrm{SiC} / \mathrm{Ni}$ [16], Sn/Ni-7 wt. \%V [17], $\mathrm{Fe}_{3} \mathrm{Si} / \mathrm{Zn}$ 
[18] and $\mathrm{Ni}_{3} \mathrm{Si} / \mathrm{Zn}$ [19-20]. Recently Liu et al. [21] observed the periodic layered structure with alternating layers in the reactions of $\mathrm{FeCr}$ alloys and molten $\mathrm{Zn}$. However, the information about the periodic layered structure formed in hot hip galvanizing is still insufficient.

In this work, the formation of periodic layered structure during hot-dip galvanizing in $\mathrm{Al}-\mathrm{Zn}-\mathrm{Mg}$ bath, with different $\mathrm{Al}$ and $\mathrm{Mg}$ contents and immersion time was investigated.

\section{Experimental procedure}

\subsection{Sample preparation}

Q235 steel (ASTM A284 Grade D), the composition of which is shown in Table 1, is selected as sample material. The steel is cut into regular shape with the dimension of $10 \mathrm{~mm} \times$ $10 \mathrm{~mm} \times 3 \mathrm{~mm}$ by wire electric discharge machine. The bath materials, $99.99 \%$ purity $\mathrm{Zn}, \mathrm{Al}$ ingots and $\mathrm{Mg}-\mathrm{Al}$ alloy are melted in the KGPS-30-8 medium frequency induction furnace. The designed composition of all baths and corresponding dipping temperature are listed in Table 2. The Mg additions in this work are designed according to the research of Wang [10], who found that the corrosion resistance of $45 \mathrm{Al}-\mathrm{Zn}$ coating was significantly improved when the $\mathrm{Mg}$ additions were in the range of 0.5 to $3.0 \mathrm{wt} . \%$.

Prior to hot dipping, the steel substrates are firstly degreased in alkaline solution for 4 minutes at $75{ }^{\circ} \mathrm{C}$, followed by rinsing in water, and pickling in hydrochloric for 3 minutes at $75^{\circ} \mathrm{C}$. Secondly, the steel specimens are covered by a flux, the constituent of which is shown in Table 3, for 3 minutes at $75^{\circ} \mathrm{C}$, and then dried for 10 minutes at $90{ }^{\circ} \mathrm{C}$. Thirdly, the steel substrates are dipped in $\mathrm{Al}-\mathrm{Zn}-\mathrm{Mg}$ baths for $10 \mathrm{~s}, 20 \mathrm{~s}, 40 \mathrm{~s}, 60 \mathrm{~s}, 80 \mathrm{~s}$ or $120 \mathrm{~s}$, then withdrawn 
from the baths and cooled in water. Finally, the steel substrates are embedded in resin, followed by polishing to a mirror surface and corroded by 10 vol. $\% \mathrm{HNO}_{3}$ solution.

\subsection{Sample characterization}

The CQ-45B2 optical microscopy (OM) and JSM-6360 scanning electron microscopy equipped with an energy dispersive spectroscopy (SEM-EDS) are conducted to analyze the structure and the composition of the phases. The ESCALAB-250Xi X-ray photoelectron spectrometer (XPS) with an Al Ka X-ray source and a $650 \mu \mathrm{m}$ measuring spot diameter, is carried out in order to reveal information about the state of the chemical bond of the specific elements on the periodic layered structure. D/MAX-2500 X-ray diffraction (XRD) with $\mathrm{Cu}$ $\mathrm{K} \alpha$ radiation coupling continuous scanning at $40 \mathrm{kV}$ and $40 \mathrm{~mA}$ is performed to determine the phases in the coatings. The sample is scanned with $2 \theta$ ranging from $10^{\circ}$ to $90^{\circ}$, the scanning speed of $5 \%$ min and step space of $0.02^{\circ}$.

\section{Results and Discussion}

\subsection{Microstructure and phase constituent of the periodic layered structure}

As the microstructure and phase constituent of the coatings consisting of the periodic layered structure are similar, the sample dipped in $55 \mathrm{Al}-\mathrm{Zn}-0.5 \mathrm{Mg}$ bath for $60 \mathrm{~s}$ at $610{ }^{\circ} \mathrm{C}$ with typical periodic layered structure, is illustrated as follows as a representative.

Fig. 1(a) shows the overview of the whole coating and Fig. 1(b) is the detail view of the area near the substrate. The periodic layered structure consists of alternating light gray layer and dark gray layer. The individual layer is parallel to the substrate. Fig. 2 presents the SEM 
mapping of the region in Fig. 1(b). The SEM mapping analysis shows that $\mathrm{Mg}$ is homogeneously distributed over the whole coating. To indentify the nature of $\mathrm{Mg}$ in the coatings, XPS analysis is carried out. From Fig. 3, it can be gained that the binding energy of $\mathrm{Mg}$ is $1303.5 \mathrm{eV}$. According to the study of Fuggle et al. [22], Mg exists in its elemental form. The above analysis indicates that $\mathrm{Mg}$ does not take part in the formation of intermetallic compound.

The morphology of the dark gray dendritic layers are analogous to that of the overlay (or solidified bath) shown in Fig. 4. Selverian et al. [23] found that three features, i.e. the alpha Al dendrite size, the Zn-rich interdendritic regions and the Si particles defined the part of the coating in 55Al-Zn-Si (Galvalume) referred to as the overlay. According to the Al-Zn binary phase diagram [24], as the 55Al-Zn bath solidifies from $610{ }^{\circ} \mathrm{C}$, the $\mathrm{Al}-\mathrm{Zn}$ liquid decomposes into Al-rich and $\mathrm{Zn}$-rich solution. On the basis of above analyses, it can be deduced that the dark gray layers consist of $\mathrm{Al}$ dendrites and $\mathrm{Zn}$-rich interdendritic regions, marked as $(\mathrm{Al}+\mathrm{Zn})$ layer.

To analyze the light gray layers of Fig. 1(a), the compositions of areas marked A, B, C, $\mathrm{D}, \mathrm{E}$ and $\mathrm{F}$ is ascertained by EDS. The compositions of areas B, C, D, E and F correspond to $\mathrm{Fe}_{23.06} \mathrm{Al}_{72.49} \mathrm{Zn}_{4.45}, \quad \mathrm{Fe}_{22.69} \mathrm{Al}_{72.74} \mathrm{Zn}_{4.57}, \quad \mathrm{Fe}_{22.30} \mathrm{Al}_{73.04} \mathrm{Zn}_{4.66}, \quad \mathrm{Fe}_{20.43} \mathrm{Al}_{73.04} \mathrm{Zn}_{5.53} \quad$ and $\mathrm{Fe}_{19.01} \mathrm{Al}_{74.55} \mathrm{Zn}_{6.44}$, respectively. The $\mathrm{Al}$ and $\mathrm{Fe}$ content in the five areas is similar. The composition of area $\mathrm{A}$, close to the substrate, is $\mathrm{Fe}_{28.50} \mathrm{Al}_{65.56} \mathrm{Zn}_{5.93}$. According to the EDS analysis, it can be deduced that the composition of light gray layer near the substrate is different from the outer alternating light gray layers. Then, XRD analysis is carried to obtain more information about the phases of the coating. Close to the sample surface (roughly 
corresponding to line 1 from the right SEM micrograph of Fig. 5), (Al), (Zn) and $\mathrm{FeAl}_{3}$ are identified by XRD analysis as shown in Fig. 5(a). After grinding with SiC paper to remove the first approximate $300 \mu \mathrm{m}$ (roughly corresponding to line 2), the (Al), ( $\mathrm{Zn}$ ) and $\mathrm{FeAl}_{3}$ are found to be the dominant phases via XRD analysis in Fig. 5(b). (Al), (Zn) and $\mathrm{FeAl}_{3}$ are identified again in the XRD patterns of Fig. 5(c) in the section after grinding the second approximate $300 \mu \mathrm{m}$ (roughly corresponding to line 3 ). The distinct phases identified in the XRD patterns of Fig. 5(d), which are obtained at the region near the substrate of the sample after removing the third approximate $300 \mu \mathrm{m}$ (roughly corresponding to line 4), are (Fe), (Al), (Zn), $\mathrm{FeAl}_{3}$ and $\mathrm{Fe}_{2} \mathrm{Al}_{5}$. According to the study of Peng et al. [25, 26], $\mathrm{Zn}$ dissolved within $\mathrm{FeAl}_{3}$ and $\mathrm{Fe}_{2} \mathrm{Al}_{5}$ during the reactions between the Fe substrate and $\mathrm{Al}-\mathrm{Zn}$ baths. On the basis of the above results, combining the informations in literatures [25-27], it can be deduced that the inner light gray layer near the substrate belongs to $\mathrm{Fe}_{2} \mathrm{Al}_{5} \mathrm{Zn}_{\mathrm{x}}$ and outer light gray layers to $\mathrm{FeAl}_{3} \mathrm{Zn}_{\mathrm{x}}$.

The ordering of phases in the coatings that are identified by XRD, is determined by line scan analysis. The scanning line is perpendicular to the interface, between the substrate and the coating, as shown in Fig. 6. The SEM-EDS line scan results show that the concentration of $\mathrm{Al}$ and $\mathrm{Fe}$ presents a periodic variation between the coating surface and the light gray layer close to the substrate.

The ordering of individual phases in the periodic layered structure is schematically presented in Fig. 7. A light gray $\mathrm{FeAl}_{3} \mathrm{Zn}_{\mathrm{x}}$ layer and a dark gray $(\mathrm{Al}+\mathrm{Zn})$ layer is defined as a layer pair. The periodic layered structure consists of multiple layer pairs. In addition, the coating contains a thin light gray layer near the substrate which is identified as $\mathrm{Fe}_{2} \mathrm{Al}_{5} \mathrm{Zn}_{\mathrm{x}}$. 


\subsection{Effect of immersion time on periodic layered structure}

The samples dipped in $45 \mathrm{Al}-\mathrm{Zn}-0.5 \mathrm{Mg}$ and $55 \mathrm{Al}-\mathrm{Zn}-0.5 \mathrm{Mg}$ baths for different immersion times are characterized and analyzed in details, as illustrated in Fig. 8 and 9 respectively.

Fig. 8 represents the SEM micrographs of the coatings, obtained by dipping Q235 steel substrates in $45 \mathrm{Al}-\mathrm{Zn}-0.5 \mathrm{Mg}$, for different immersion times at $590{ }^{\circ} \mathrm{C}$. At the beginning of hot dipping for relatively short immersion time, $10 \mathrm{~s}$, the coating consists of a $\mathrm{Fe}_{2} \mathrm{Al}_{5} \mathrm{Zn}_{\mathrm{x}}$ layer, a $\mathrm{FeAl}_{3} \mathrm{Zn}_{\mathrm{x}}$ layer and a $(\mathrm{Al}+\mathrm{Zn})$ layer, similar to the common microstructure formed during Al-Zn hot-dip galvanizing in literatures [2-4,23], as illustrated in Fig. 8(a). When the immersion time increases to $20 \mathrm{~s}$, the periodic layered structure with few layer pairs is formed in the coating, as shown in Fig. 8(b). With the further increase of immersion time, the number of the layer pair continues increasing, as represented in Fig. 8(c), (d) and (e). And when the immersion time is $80 \mathrm{~s}$, the periodic layered structure becomes the most pronounced, compared to $40 \mathrm{~s}$ and $60 \mathrm{~s}$. When the steel substrate is immersed for a period of time longer than $120 \mathrm{~s}$, the periodic layered structure begins to deteriorate and the banded $\mathrm{FeAl}_{3} \mathrm{Zn}_{\mathrm{x}}$ layers near the sample surface are transformed to blocky compounds, as shown in Fig. 8(f).

Fig. 9 shows the SEM micrographs of the coatings obtained by dipping the steel substrates in $55 \mathrm{Al}-\mathrm{Zn}-0.5 \mathrm{Mg}$, for different immersion times at $610{ }^{\circ} \mathrm{C}$. When the immersion time is $10 \mathrm{~s}$, the periodic layered structure with few layer pairs is formed in the coating, as represented in Fig. 9(a). As the immersion time continues increasing, the layer pair increases and the periodic layered structure becomes more and more pronounced, as illustrated in Fig. 
9(b), (c) and (d). When the immersion time is $80 \mathrm{~s}$, the periodic layered structure begins to deteriorate and the banded $\mathrm{FeAl}_{3} \mathrm{Zn}_{\mathrm{x}}$ layers close to sample surface are transformed to blocky $\mathrm{FeAl}_{3} \mathrm{Zn}_{\mathrm{x}}$, as shown in Fig. 9(e). As the sample immerses for a longer time, $120 \mathrm{~s}$, more band $\mathrm{FeAl}_{3} \mathrm{Zn}_{\mathrm{x}}$ layers are transformed to blocky compounds, as illustrated in Fig. 9(f).

According to above experimental results, it can be found that the formation of periodic layered structure requires an incubation period marked as $t_{1}$, while as the immersion time reaches another period marked as $t_{2}$, the periodic layered structure begins to be destroyed. Therefore, the model of the development of the periodic layered structure with the immersion time is built, as presented in Fig. 10. When the immersion time is shorter than $t_{1}$, the periodic layered structure is not formed. As the time is in the range of $t_{1}$ to $t_{2}$, the layer pairs increase with the immersion time, while if the immersion time is over $t_{2}$, the periodic layered structure begins to be destroyed. As Liu et al. [21] investigated the formation kinetics of the periodic layered structures in Fe30Cr70/Zn system, they also found that formation of periodic layered structure require an incubation period. And when the immersion time is too long, the growth rate of $\mathrm{Fe}-\mathrm{Al}$ intermetallic layer decreases, the $\mathrm{Fe}-\mathrm{Al}$ intermetallic layer is gradually attacked by the liquid phase of the bath according to Chen et al. [28] and Nishimoto et al. [29]. Thus the banded $\mathrm{FeAl}_{3} \mathrm{Zn}_{\mathrm{x}}$ layers is attacked by liquid phase from bath and transformed to blocky ones.

\subsection{Effect of Al content on the periodic layered structure}

The structures of the coatings obtained in $\mathrm{Al}-\mathrm{Zn}-0.5 \mathrm{Mg}$ baths for 40 and $80 \mathrm{~s}$, with $\mathrm{Al}$ content in the range of 15 to $55 \mathrm{wt} . \%$, is presented in Fig. 11 and 12 respectively. 
When the $\mathrm{Al}$ content in $\mathrm{Al}-\mathrm{Zn}-0.5 \mathrm{Mg}$ bath is $15 \mathrm{wt} . \%$, the coating immersed in the bath for $40 \mathrm{~s}$ consists of a $\mathrm{Fe}_{2} \mathrm{Al}_{5} \mathrm{Zn}_{\mathrm{x}}$ layer, a $\mathrm{FeAl}_{3} \mathrm{Zn}_{\mathrm{x}}$ layer and a $(\mathrm{Al}+\mathrm{Zn})$ layer. As the $\mathrm{Al}$ content increases to 25 or $35 \mathrm{wt} \%$, many cracks parallel to the substrate appear within the intermetallic layer. When the $\mathrm{Al}$ content in the bath is $45 \mathrm{wt} \%$, the periodic layered structure with few layer pairs is formed. As the $\mathrm{Al}$ content increases to $55 \mathrm{wt} \%$, the layer pair increases and the periodic layered structure becomes more pronounced.

When the $\mathrm{Al}$ content in $\mathrm{Al}-\mathrm{Zn}-0.5 \mathrm{Mg}$ bath is $15 \mathrm{wt} . \%$, the microstructure of the coating obtained for $80 \mathrm{~s}$ is similar to the coating for $40 \mathrm{~s}$, but the thickness of intermetallic layer increases and the internal cracks appears. As the $\mathrm{Al}$ content increases to $25 \mathrm{wt} \%$, more cracks appear within the intermetallic layer. When the $\mathrm{Al}$ content increases to $35 \mathrm{wt} \%$, the periodic layered structure with few layer pairs is formed. As the Al content in the bath is 45 wt.\%, the layer pair increases and the periodic layered structure becomes more pronounced. When the $\mathrm{Al}$ content increases to $55 \mathrm{wt} \%$, the periodic layered structure begins to deteriorate and the banded $\mathrm{FeAl}_{3} \mathrm{Zn}_{\mathrm{x}}$ layers near sample surface are transformed to blocky $\mathrm{FeAl}_{3} \mathrm{Zn}_{\mathrm{x}}$.

According to the experimental results, it can be concluded that the $\mathrm{Al}$ content in bath could affect the transformation process of the periodic layered structure. The incubation period $t_{1}$ of the formation of periodic layered structure is shortened as the Al content increases. In addition, the immersion time $t_{2}$ for the deterioration of the periodic layered structure is reduced with the increase of $\mathrm{Al}$ content. The growth of intermetallic layer between substrate and overlay layer is controlled by the reaction between Fe from the substrate and $\mathrm{Al}$ from the bath $[30,31]$. When the $\mathrm{Al}$ content in bath increases, the reaction of $\mathrm{Fe}-\mathrm{Al}$ aggravates and $\mathrm{FeAl}_{3} \mathrm{Zn}_{\mathrm{x}}$ layers grow faster. Thus, the incubation period of the periodic layered structure is 
shortened.

\subsection{Effect of $M g$ addition on the periodic layered structure}

The samples dipped in 45Al-Zn and 55Al-Zn baths for $40 \mathrm{~s}$ with different $\mathrm{Mg}$ additions are investigated, as represented in Fig. 13 and 14 respectively.

The scanning SEM micrographs of the coatings obtained in $45 \mathrm{Al}-\mathrm{Zn}$ baths, for different $\mathrm{Mg}$ additions for 40s, are represented in Fig. 13. When Mg addition is $0.5 \mathrm{wt} \%$, the periodic layered structure with few layer pairs is formed in the coating. When the $\mathrm{Mg}$ addition increases to $1.5 \mathrm{wt} . \%$, the layer pairs increase and the periodic layered structure becomes distinct. When $\mathrm{Mg}$ addition is 2.5 wt.\%, the banded $\mathrm{FeAl}_{3} \mathrm{Zn}_{\mathrm{x}}$ layers close to the sample surface are destroyed. When the $\mathrm{Mg}$ addition increases to $3.0 \mathrm{wt} . \%$, all banded $\mathrm{FeAl}_{3} \mathrm{Zn}_{\mathrm{x}}$ layers in the periodic arrangement are replaced by blocky $\mathrm{FeAl}_{3} \mathrm{Zn}_{\mathrm{x}}$.

Fig. 14 shows the SEM micrographs of the coatings obtained by dipping steel substrate in 55\% Al-Zn baths, for different $\mathrm{Mg}$ additions for $40 \mathrm{~s}$. When the $\mathrm{Mg}$ addition is $0.5 \mathrm{wt} . \%$, the distinct periodic layer is formed in the coating. As the Mg addition increases to $1.5 \mathrm{wt} \%$, the periodic layered structure is completely destroyed.

According to the above experimental results, as the $\mathrm{Al}$ content is constant, the incubation period $t_{1}$ and destruction time $t_{2}$ of the periodic layered structure is reduced with the increasing of $\mathrm{Mg}$ addition. The experimental results in 3.1 indicate that $\mathrm{Mg}$ does not take part in the formation of intermetallic compound and it exists in the coatings as elemental form. Unwin et al. [5] and Tong et al. [32] proposed that $\mathrm{Mg}$ addition in the Al-Zn bath promoted the interface reaction and the growth of the $\mathrm{Fe}-\mathrm{Al}$ intermetallic layer, making the intermetallic 
denser, due to the implementation of grain refining. Therefore, $\mathrm{Mg}$ refines the grain of the coating and then affect the transformation kinetics of the periodic layered structure.

This work investigates the effect of $\mathrm{Al}$ and $\mathrm{Mg}$ content and immersion time on the periodic layered structure in details, and the formation mechanism of the periodic layered structure will be investigated in next paper, on the basis of additional experiments.

\section{Conclusions}

The effect of immersion time, $\mathrm{Mg}$ additions and $\mathrm{Al}$ content, on the periodic layered structure in $\mathrm{Al}-\mathrm{Zn}-\mathrm{Mg}$ coatings are investigated. The following conclusions could be drawn from the present study:

1. The alternating layers of the periodic layered structure consist of a $\mathrm{FeAl}_{3} \mathrm{Zn}_{\mathrm{x}}$ layer and a $(\mathrm{Al}+\mathrm{Zn})$ layer. In addition, the coating contains a thin $\mathrm{Fe}_{2} \mathrm{Al}_{5} \mathrm{Zn}_{\mathrm{x}}$ layer existing between the substrate and the periodic layered structure.

2. The formation of the periodic layered structure requires an incubation period $t_{1}$. In addition, when the immersion time is over $\mathrm{t}_{2}$, the periodic layered structure is destroyed by the liquid phase of the bath.

3. The incubation period $t_{1}$ when periodic layered structure is formed and the immersion time $t_{2}$ when periodic layered structure is destroyed, is shorten with the increase of $\mathrm{Al}$ content and $\mathrm{Mg}$ addition.

\section{Acknowledgments}

This investigation is supported by the National Science Foundation of the China (No.51471140), the Ph. D. Programs Foundation of Ministry of Education of China 
(No.20134301110006) and Scientific Research Fund of Hunan Provincial Educational Department (No.14A143). 


\section{References}

[1] A. R. Marder, The metallurgy of zinc-coated steel, Progr. Mater. Sci. 45 (2000) 191-271.

[2] D. Phelan, B. J. Xu, R. Dippenaar, Formation of intermetallic phases on 55 wt.\% Al-Zn-Si hot dip strip, Mater. Sci. Eng. A. 420 (2006) 144-149.

[3] F. García, A. Salinas, E. Nava, The role of Si and Ti additions on the formation of the alloy layer at the interface of hot-dip Al-Zn coatings on steel strips, Mater. Lett. 60 (2006) 775-778.

[4] G. Y. Yuan, Z. L. Liu, Q. D. Wang, et al., Microstructure refinement of $\mathrm{Mg}-\mathrm{Al}-\mathrm{Zn}-\mathrm{Si}$ alloys, Mater. Lett. 56 (2002) 53-58.

[5] P. N. T. Unwin, R. B. Nicholson, The nucleation and initial stages of growth of grain boundary precipitates in Al-Zn-Mg and Al-Mg alloys, Acta. Metall. 17 (1969) 1379-1393.

[6] E. De Bruycker, B. C. De Cooman, M. De Meyer, Experimental study and microstructure simulation of Zn-Al-Mg coatings, Rev. Metall. 102 (2005) 543-550.

[7] M. Dutta, A. K. Halder, S. B. Singh, Morphology and properties of hot dip Zn-Mg and Zn-Mg-Al alloy coatings on steel sheet, Surf. Coat. Technol. 205 (2010) 2578-2584.

[8] E. Diler, B. Rouvellou, S. Rioual, et al., Characterization of corrosion products of Zn and $\mathrm{Zn}-\mathrm{Mg}-\mathrm{Al}$ coated steel in a marine atmosphere, Corros. Sci. 87 (2014) 111-117.

[9] N. LeBozec, D. Thierry, M. Rohwerder, et al., Effect of carbon dioxide on the atmospheric corrosion of $\mathrm{Zn}-\mathrm{Mg}-\mathrm{Al}$ coated steel, Corros. Sci. 74 (2013) 379-386.

[10] T. Wang, Study on Structure and Corrosion Resistance of Zinc-Aluminium Based Alloy Coatings, Master's Thesis, The College of Material Science and Engineering at Xiangtan University, China. (2013) 20-29.

[11] R. Liesegang, Ueber einige eigenschaften von gallerten, Naturwiss. Wochenschr. 10 (1896) 353-362.

[12] K. Osinski, A. W. Vriend, F. Bastin, et al., Periodic Formation of FeSi Bands in Diffusion Couples Fe (15 wt.\%-Si)--Zn, Z. Metallkd. 73 (1982) 258-261.

[13] S. F. Dunaev, S. A. Zver'kov, Influence of high pressure on the formation of periodic regular structures in multicomponent diffusion zones, J. Less. Common. Met. 153 (1989) 143-150. 
[14] Y. C. Chen, J. Xu, X. H. Fan, et al., The mechanism of periodic layer formation during solid-state reaction between $\mathrm{Mg}$ and $\mathrm{SiO}_{2}$, Intermetallics. 17 (2009) 920-926.

[15] Y. C. Chen, Y. G. Zhang, C. Q. Chen, Quantitative descriptions of periodic layer formation during solid state reactions, Mater. Sci. Eng. A. 362 (2003) 135-144.

[16] R. C. J. Schiepers, J. A. Van Beek, F. J. J. Van Loo, et al., The interaction between SiC and $\mathrm{Ni}, \mathrm{Fe},(\mathrm{Fe}, \mathrm{Ni})$ and steel: morphology and kinetics, J. Eur. Ceram. Soc. 11 (1993) 211-218.

[17] S. Chen, C. Chen, C. Chang, Interfacial reactions in $\mathrm{Sn} / \mathrm{Ni}-7$ wt.\% V couple, Scripta. Mater. 56 (2007) 453-456.

[18] S. Oberhauser, C. Strobl, G. Schreiber, et al., Formation of periodic patterns in the (Ni, W)/Al diffusion couples, Surf. Coat. Technol. 204 (2010) 2307-2315.

[19] X. Su, C. Gao, Z. Li, et al., The Mechanism of Periodic Layered Structure Formation in $\mathrm{Ni}_{3} \mathrm{Si} / \mathrm{Zn}$ System, J. Phase. Equilib. Diffus. 34 (2013) 416-420.

[20] Y. C. Chen, X. F. Zhang, Y. K. Ren, et al., Microstructure evolution of periodic layers formed during solid state reaction between $\mathrm{Zn}$ and $\mathrm{Ni}_{3} \mathrm{Si}$, Intermetallics, 36 (2013) 8-11.

[21] Y. Liu, M. Y. Tang, Y. Song, et al., Reactions of FeCr alloys with liquid zinc in hot-dip galvanizing, Surf. Coat. Technol. 276 (2015) 714-720.

[22] J. C. Fuggle, L. M. Watson, D. J. Fabian, et al., X-ray excited Auger and photoelectron spectra of magnesium, some alloys of magnesium and its oxide, J. Phys. F, 5 (1975) 375-383.

[23] J. H. Selverian, M. R. Notis, A. R. Marder, The microstructure of 55 w/o $\mathrm{Al}-\mathrm{Zn}-\mathrm{Si}$ (Galvalume) hot dip coatings, J. Mater. Eng. 9 (1987) 133-140.

[24] H. Araki, Y. Minamino, T. Yamane, et al., Partial phase diagrams of the aluminium-rich region of the Al-Zn system at 0.1 MPa and 2.1 GPa, J. Mater. Sci. Lett. 11 (1992) 181-183.

[25] H. P. Peng, X. P. Su, J. H. Wang, et al., Interface reaction mechanism for galvanizing in Zn-Al baths, Chin. J. Nonferrous. Met. 22 (2012) 3168-3175.

[26] H. P. Peng, X. P. Su, Z. Li, et al., Synergistic effect of $\mathrm{Cu}$ and $\mathrm{Si}$ on hot-dipping galvalume coating, Surf. Coat. Technol. 206 (2012) 4329-4334.

[27] G. Ghosh, Aluminium-Iron-Zinc, Springer-Verlag, Berlin Heidelberg. (2008) 319-348. 
[28] Z. W. Chen, J. T. Gregory, R. M. Sharp, Intermetallic phases formed during hot dipping of low carbon steel in a Zn-5 Pct Al melt at $450{ }^{\circ} \mathrm{C}$, Metall. Trans. A. 23 (1992) 2393-2400.

[29] A. Nishimoto, J. Inagaki, K. Naksoks, Effects of surface microstructure and chemical compositions of steels on formation of Fe-Zn compounds during continuous galvanizing, Trans. ISIJ. 26 (1986) 807-813.

[30] G. H. Awan, F. Ul Hasan, The morphology of coating/substrate interface in hot-dip-aluminized steels, Mater. Sci. Eng. A. 472 (2008) 157-165.

[31] P. Liberski, A. Gierek, H. Kania, et al., Formation of coatings from a liquid phase on the surface of iron-base alloys, Arch. Foundry. Eng. 8 (2008) 93-98.

[32] C. Tong, Z. Li, X. P. Su, et al., Research on Hot-dipped Zn-6\%Al-3\%Mg Alloy Coatings Intermetallics Layer Growth, J. Mater. Eng. 3 (2013) 54-60. 


\section{List of Figure captions}

Fig.1. SEM micrograph of typical periodic structure in the coating obtained by dipping steel substrate in $55 \mathrm{Al}-\mathrm{Zn}-0.5 \mathrm{Mg}$ for $60 \mathrm{~s}$ at $610^{\circ} \mathrm{C}$ : (a) overview of the entire coating, (b) detail view of the area near the substrate.

Fig.2. SEM mapping to area in Fig. 1(b).

Fig.3. XPS analysis, showing the high-resolution Mg spectra of the cross section of the coating obtained by dipping steel substrate in $55 \mathrm{Al}-\mathrm{Zn}-0.5 \mathrm{Mg}$ for $60 \mathrm{~s}$ at $610{ }^{\circ} \mathrm{C}$.

Fig.4. SEM micrograph of coating obtained by dipping steel substrate in $35 \mathrm{Al}-\mathrm{Zn}-0.5 \mathrm{Mg}$ for $20 \mathrm{~s}$ at $570{ }^{\circ} \mathrm{C}$, showing the dendritic morphology of the overlay.

Fig.5. XRD of the coating obtained by dipping steel substrates in $55 \mathrm{Al}-\mathrm{Zn}-0.5 \mathrm{Mg}$ for $60 \mathrm{~s}$ at $610{ }^{\circ} \mathrm{C}$ at different sections. (a) at section 1 near the coating surface, (b) at section 2 after grinding with $\mathrm{SiC}$ paper to remove the first approximate $300 \mu \mathrm{m}$, (c) at section 3 after removing the second approximate $300 \mu \mathrm{m}$, (d) at section 4 near the substrate after removing the third approximate $300 \mu \mathrm{m}$.

Fig.6. Line scan analysis of the cross section of the coating obtained by dipping steel substrate in $55 \mathrm{Al}-\mathrm{Zn}-0.5 \mathrm{Mg}$ for $60 \mathrm{~s}$ at $610{ }^{\circ} \mathrm{C}$.

Fig.7. Diagram of ordering of phases in the periodic layered structure.

Fig.8. SEM micrographs of the coatings, obtained by dipping steel substrate in 45Al-Zn-0.5Mg for different times: (a) $10 \mathrm{~s}$, (b) $20 \mathrm{~s}$, (c) $40 \mathrm{~s}$, (d) $60 \mathrm{~s}$, (e) $80 \mathrm{~s}$, (f) $120 \mathrm{~s}$.

Fig.9. SEM micrographs of the coatings, obtained by dipping steel substrate in 55Al-Zn-0.5Mg for different times: (a) $10 \mathrm{~s}$, (b) $20 \mathrm{~s}$, (c) $40 \mathrm{~s}$, (d) $60 \mathrm{~s}$, (e) $80 \mathrm{~s}$, (f) $120 \mathrm{~s}$. 
Fig.10. Model of the development of the periodic layered structure with the increase of immersion time. The time $t_{1}$ presents the period when the periodic layered structure begins to be formed, and $t_{2}$ presents the period when the periodic layered structure begins to be destroyed.

Fig.11. SEM micrographs of the coatings, obtained by dipping steel substrate in Al-Zn- $0.5 \mathrm{Mg}$ bath with different $\mathrm{Al}$ content for $40 \mathrm{~s}$ : (a) $15 \mathrm{wt} \%$, (b) $25 \mathrm{wt} \%$, (c) $35 \mathrm{wt} \%$, (d) $45 \mathrm{wt} . \%$, (e) 55 wt. $\%$.

Fig.12. SEM micrographs of the coatings, obtained by dipping steel substrate in Al-Zn- $0.5 \mathrm{Mg}$ bath with different $\mathrm{Al}$ content for $80 \mathrm{~s}$ : (a) 15 wt.\%, (b) 25 wt.\%, (c) 35 wt.\%, (d) 45 wt.\%, (e) 55 wt. $\%$.

Fig.13. SEM micrographs of the coatings, obtained by dipping steel substrate in $45 \mathrm{Al}-\mathrm{Zn}-\mathrm{Mg}$ bath with different $\mathrm{Mg}$ additions for $40 \mathrm{~s}$ : (a) $0.5 \mathrm{wt} \%$, (b) 1.5 wt.\%, (c) 2.5 wt.\%, (d) 3.0 wt.\%.

Fig.14. SEM micrographs of the coatings, obtained by dipping steel substrate in $55 \mathrm{Al}-\mathrm{Zn}-\mathrm{Mg}$ bath with different $\mathrm{Mg}$ additions for $40 \mathrm{~s}$ : (a) $0.5 \mathrm{wt} \%$, (b) $1.5 \mathrm{wt} \%$, (c) 2.5 wt.\%, (d) 3.0 wt.\%. 

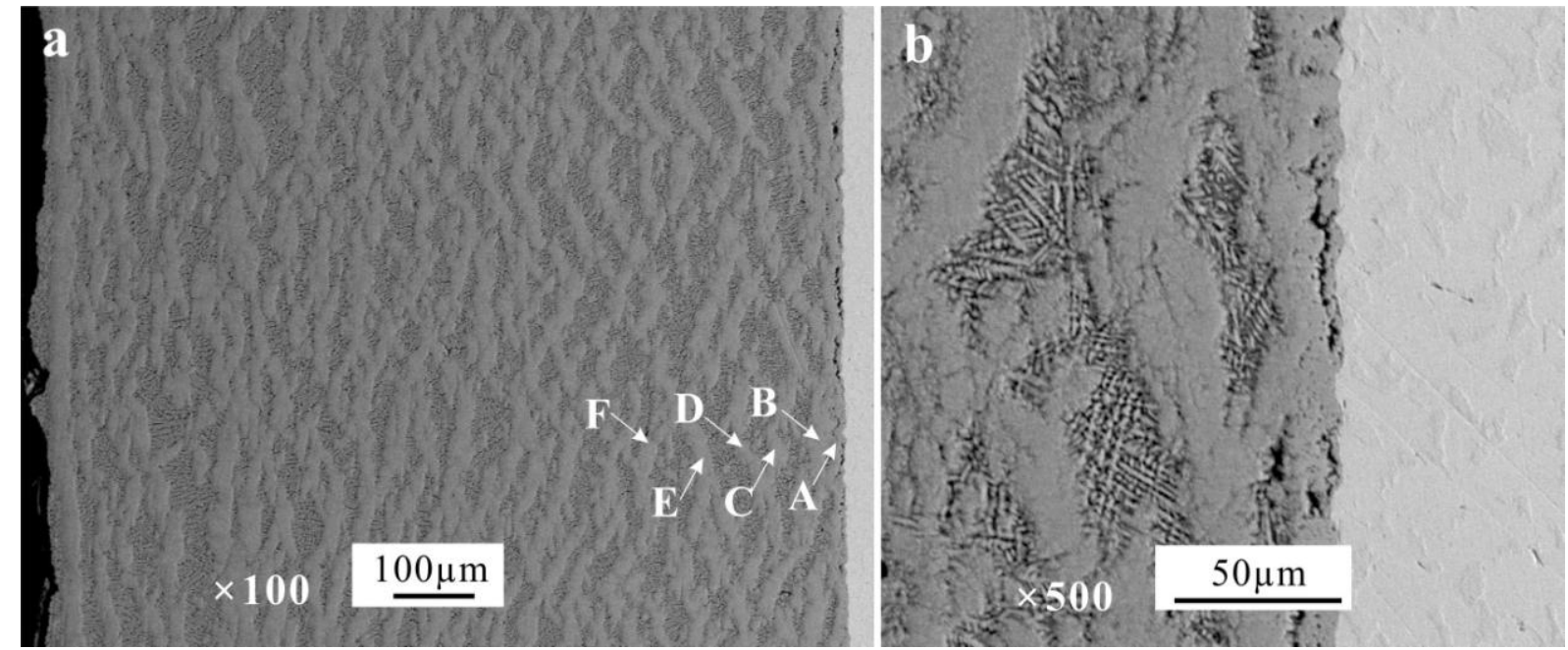

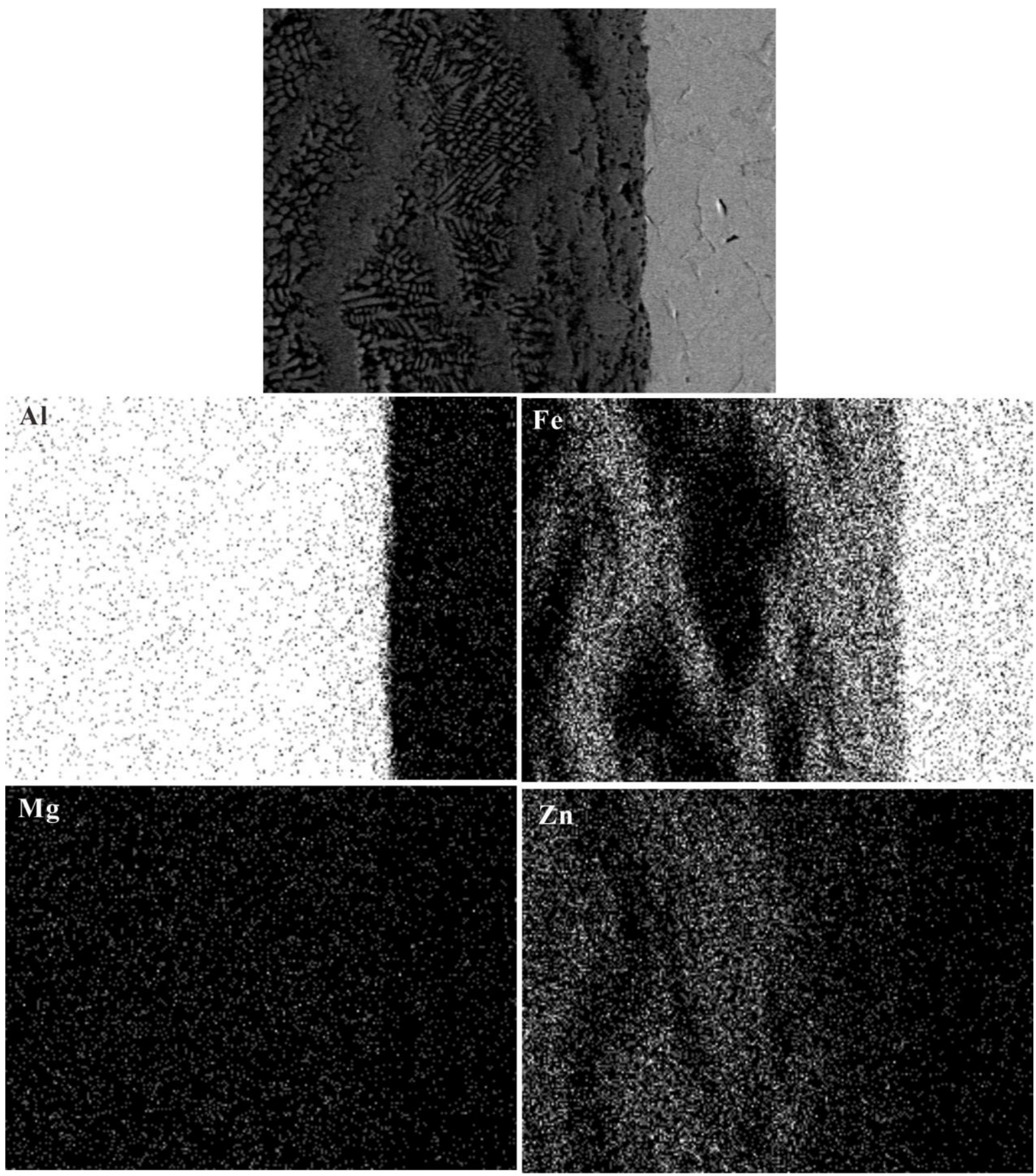


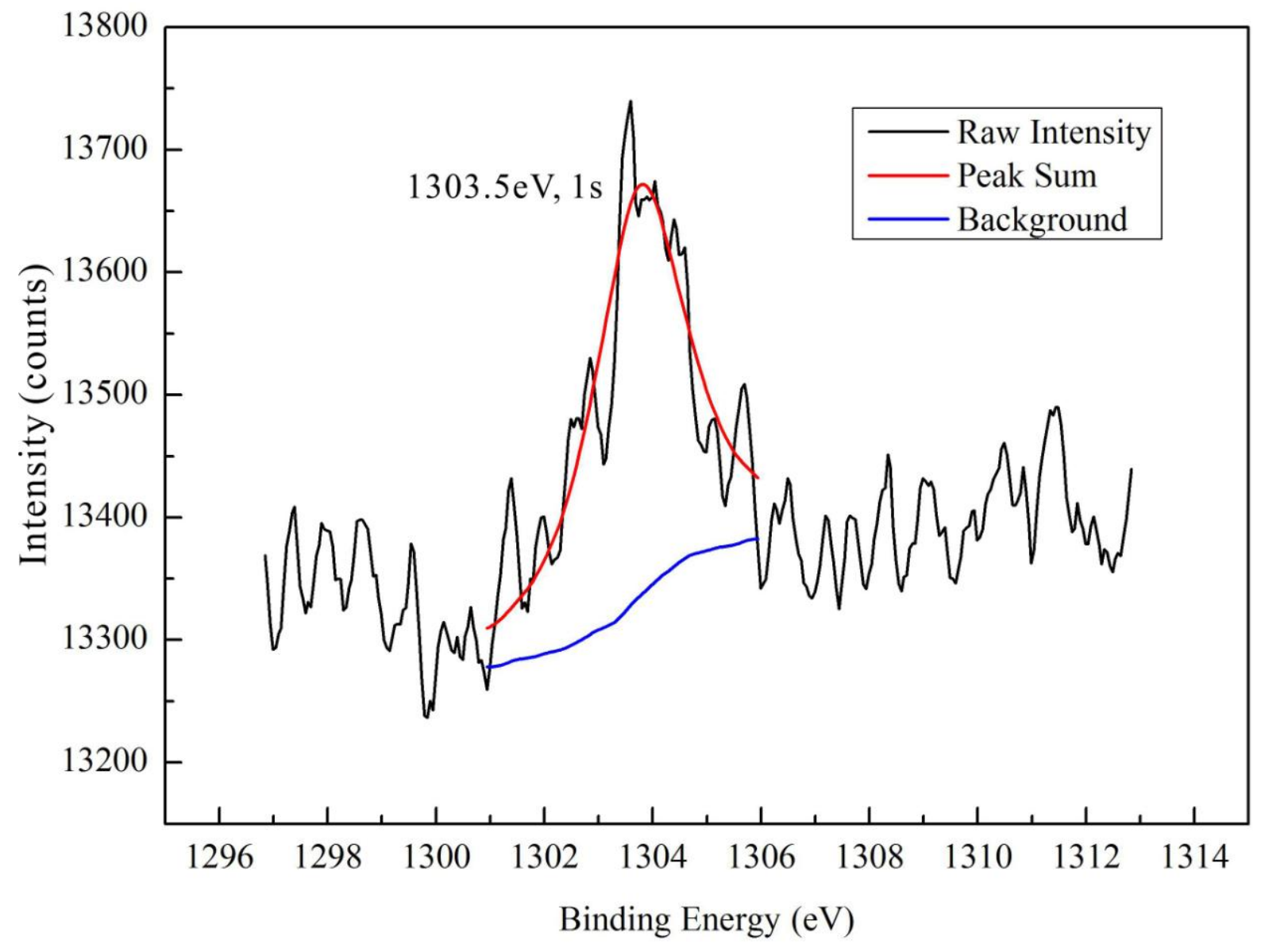




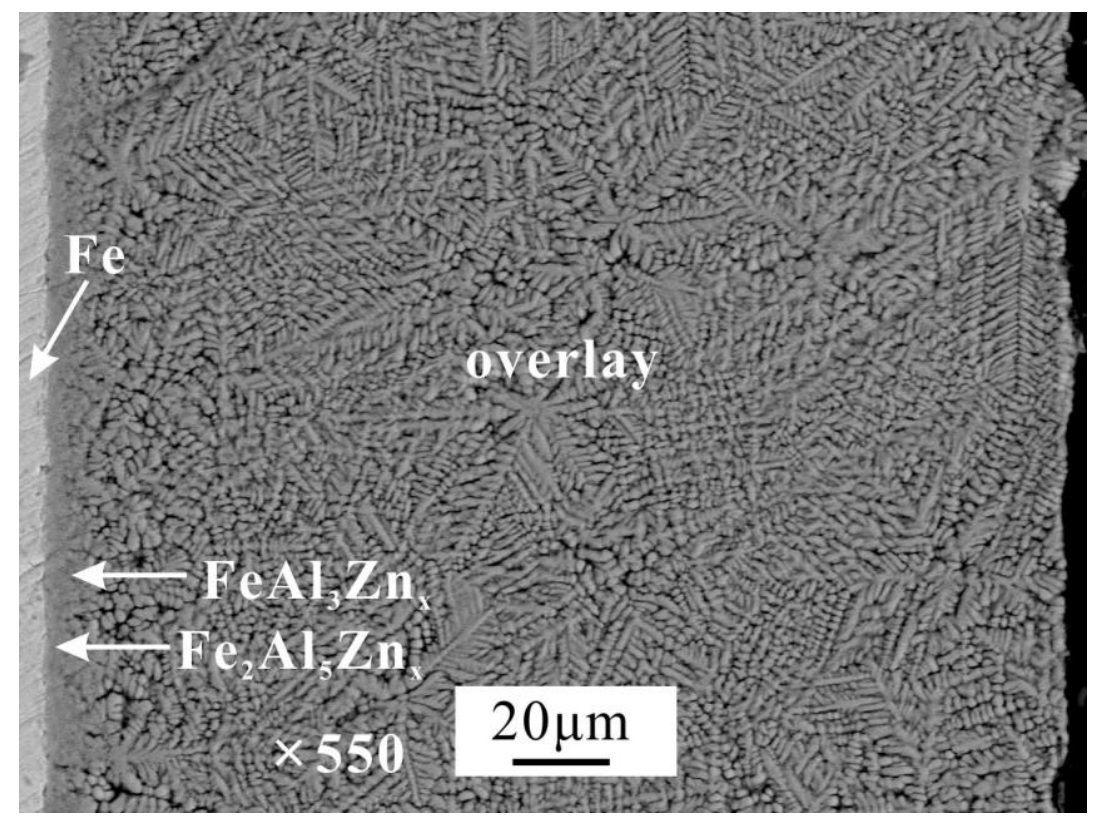




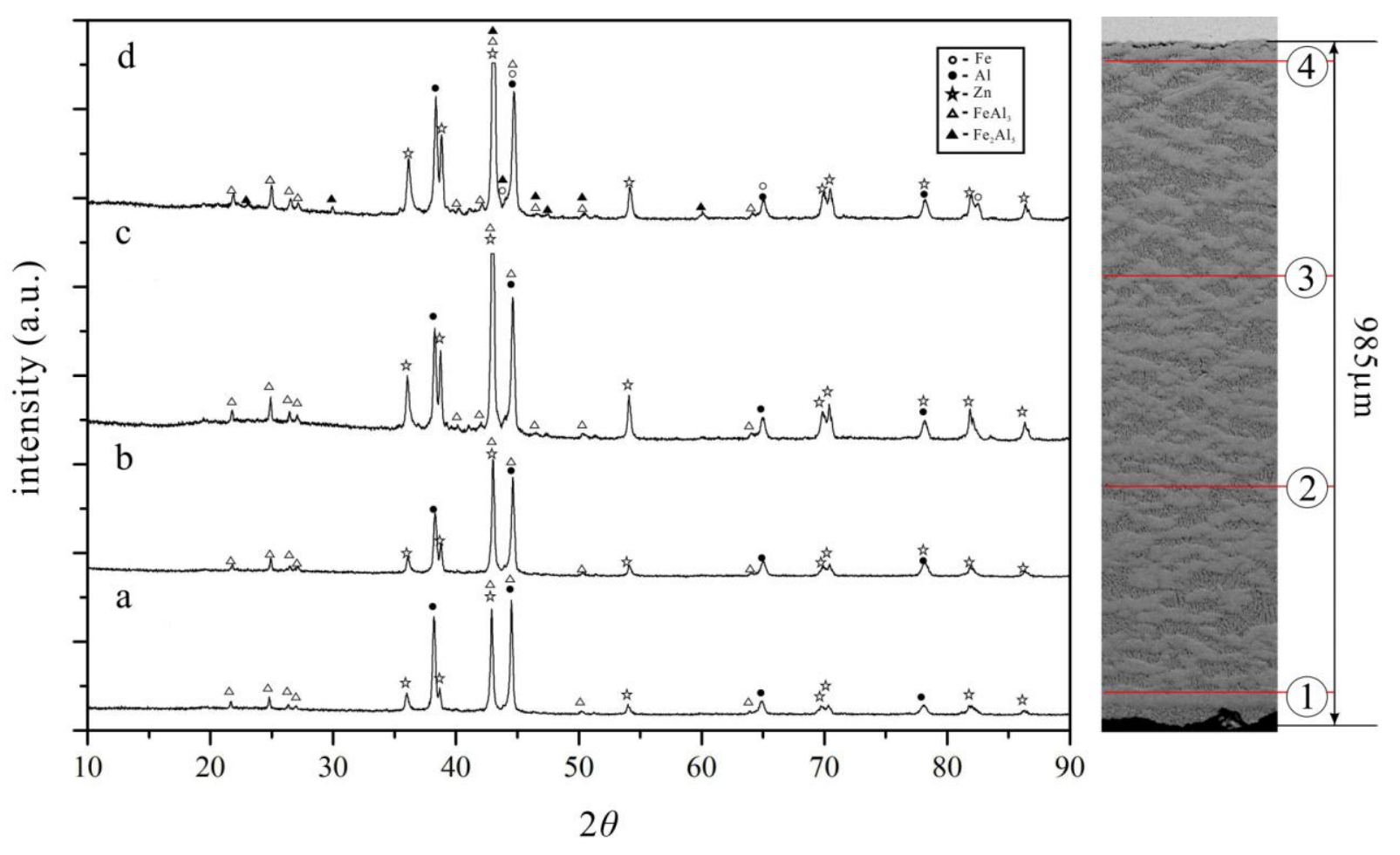




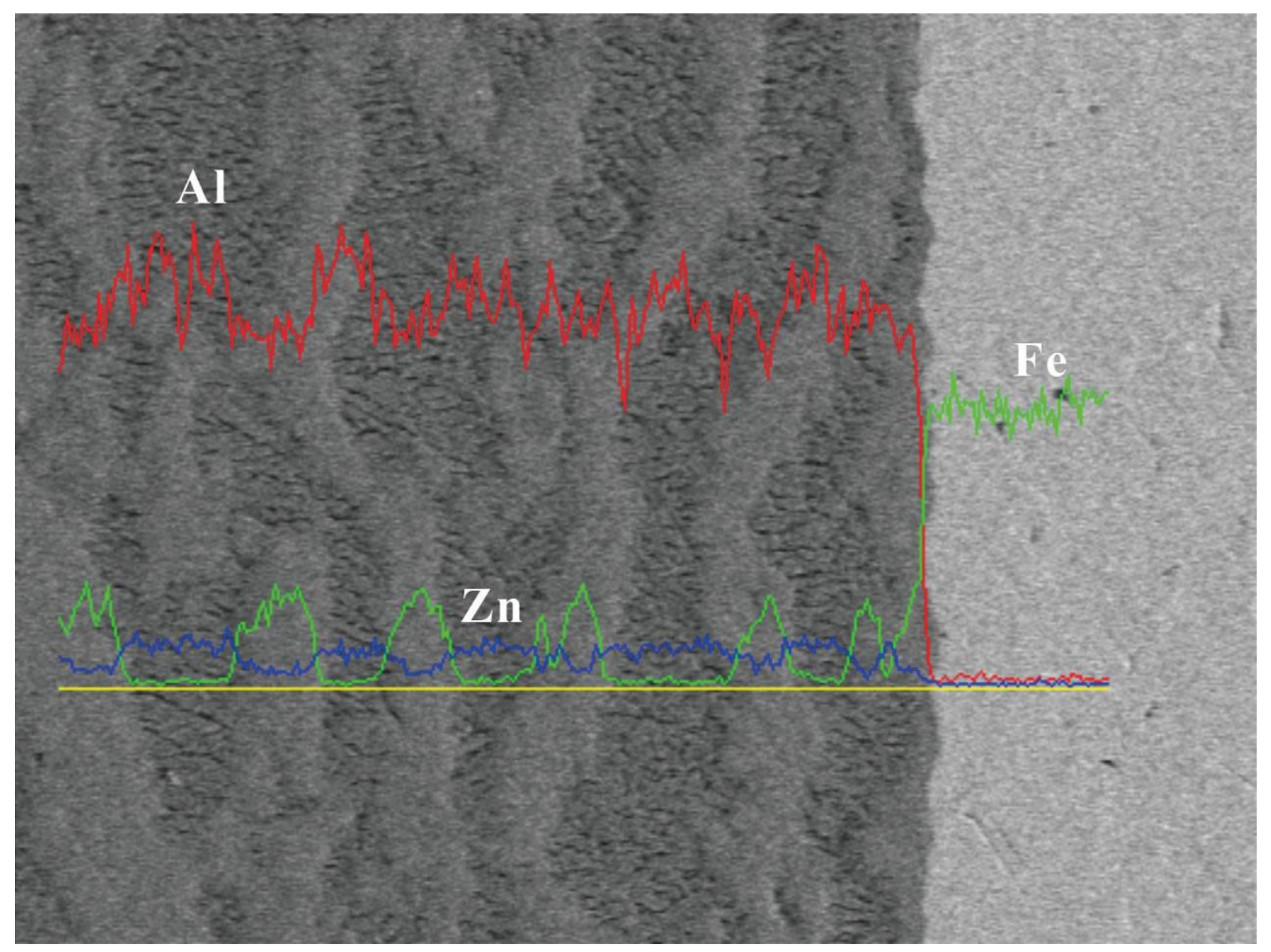




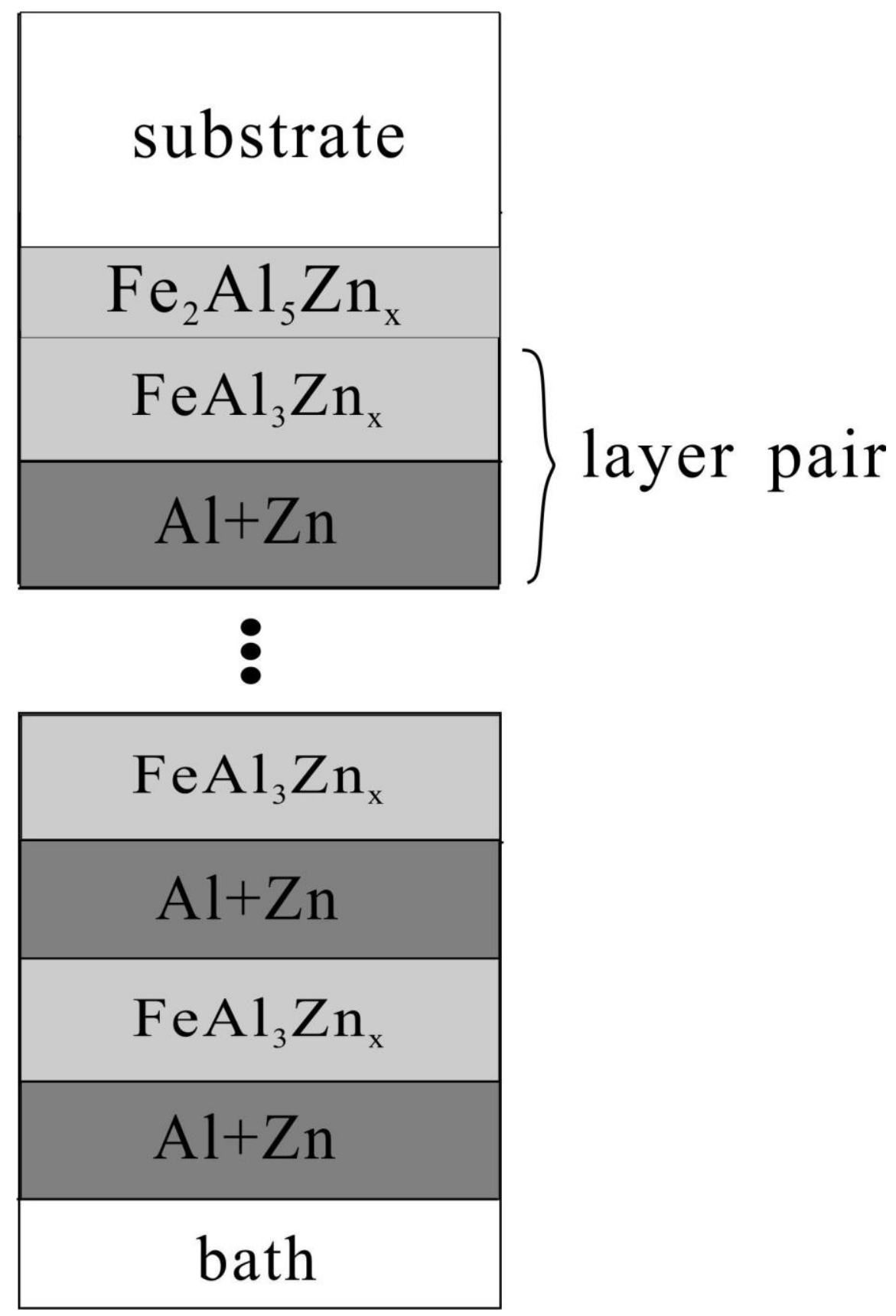




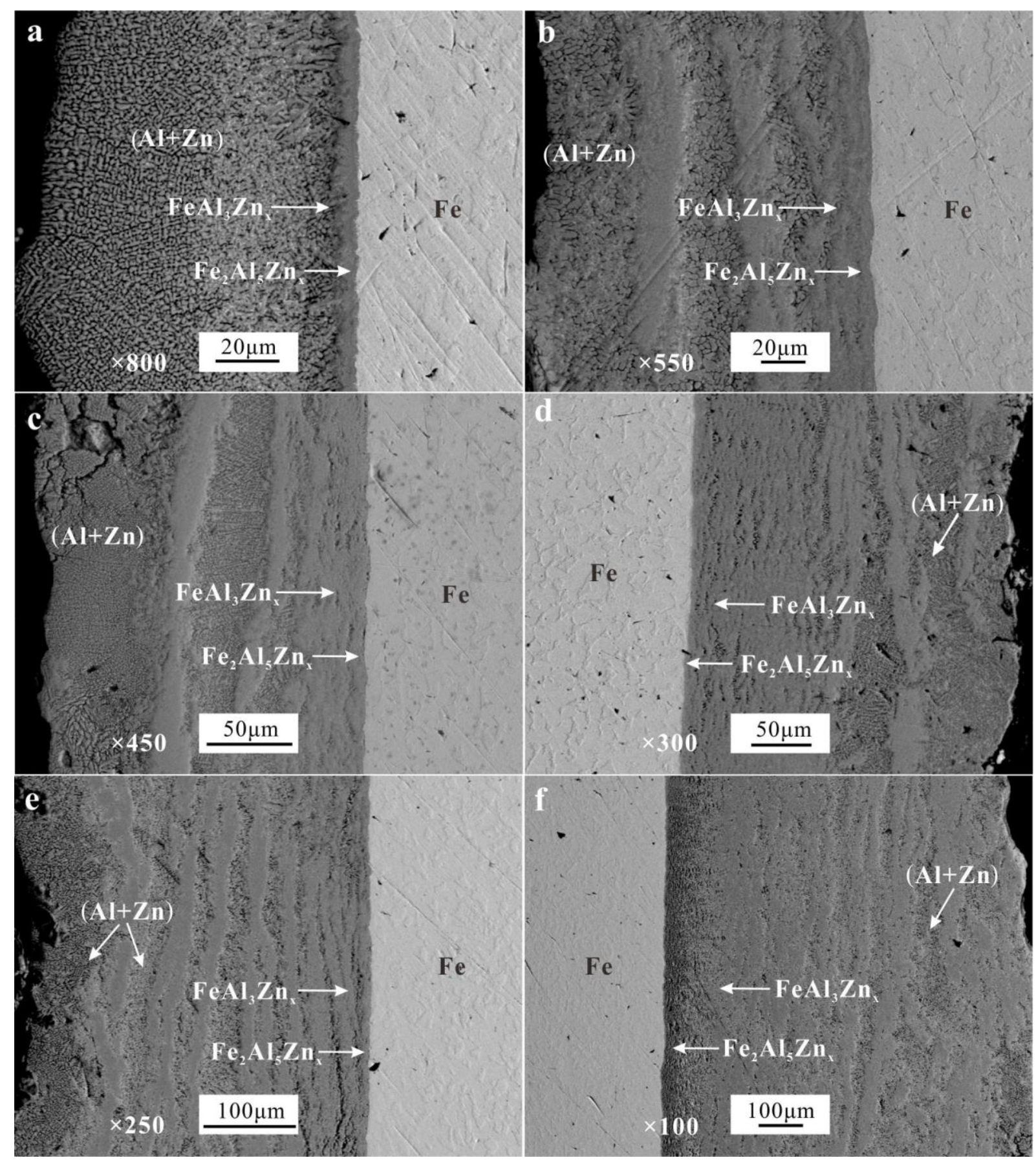




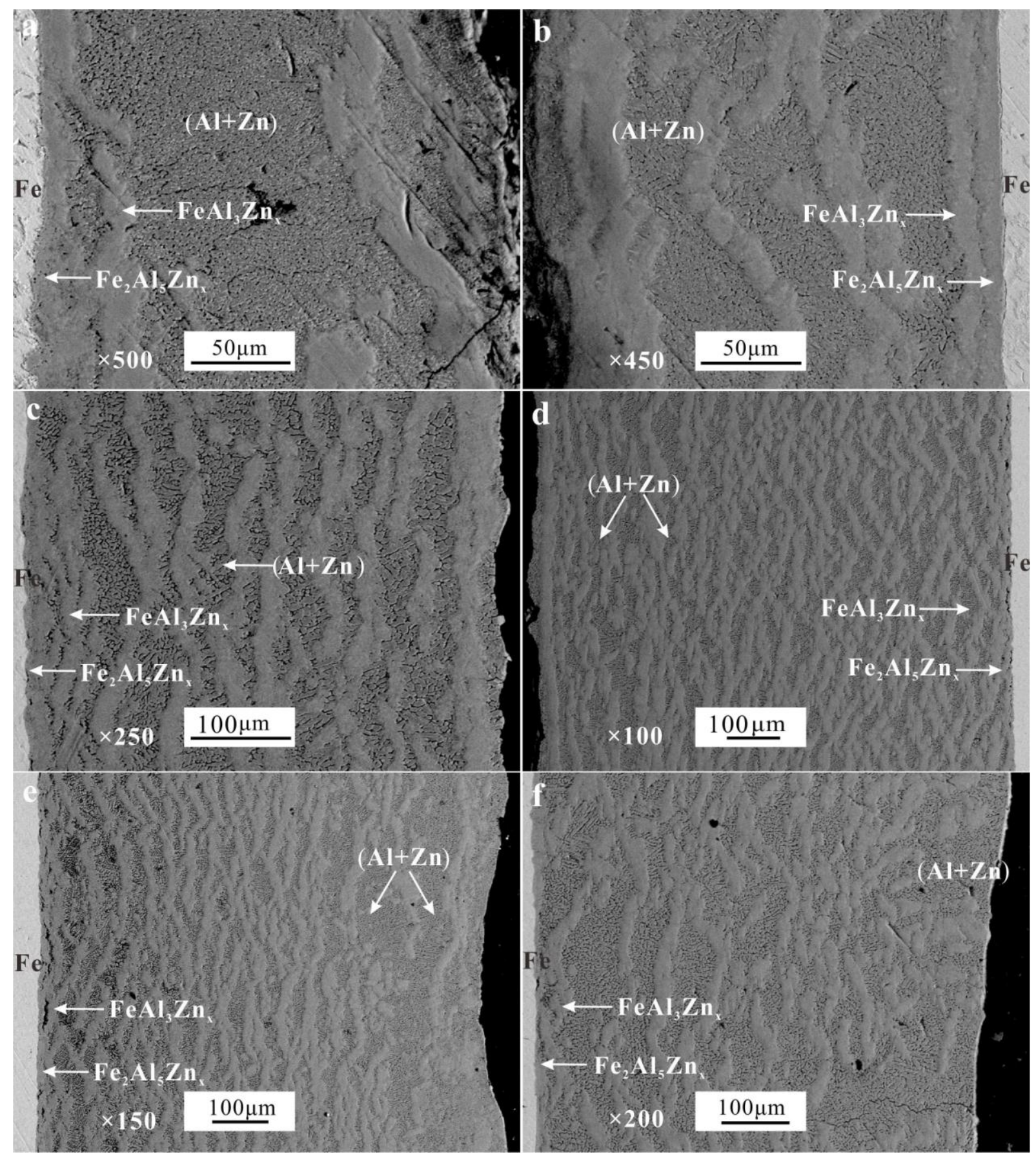




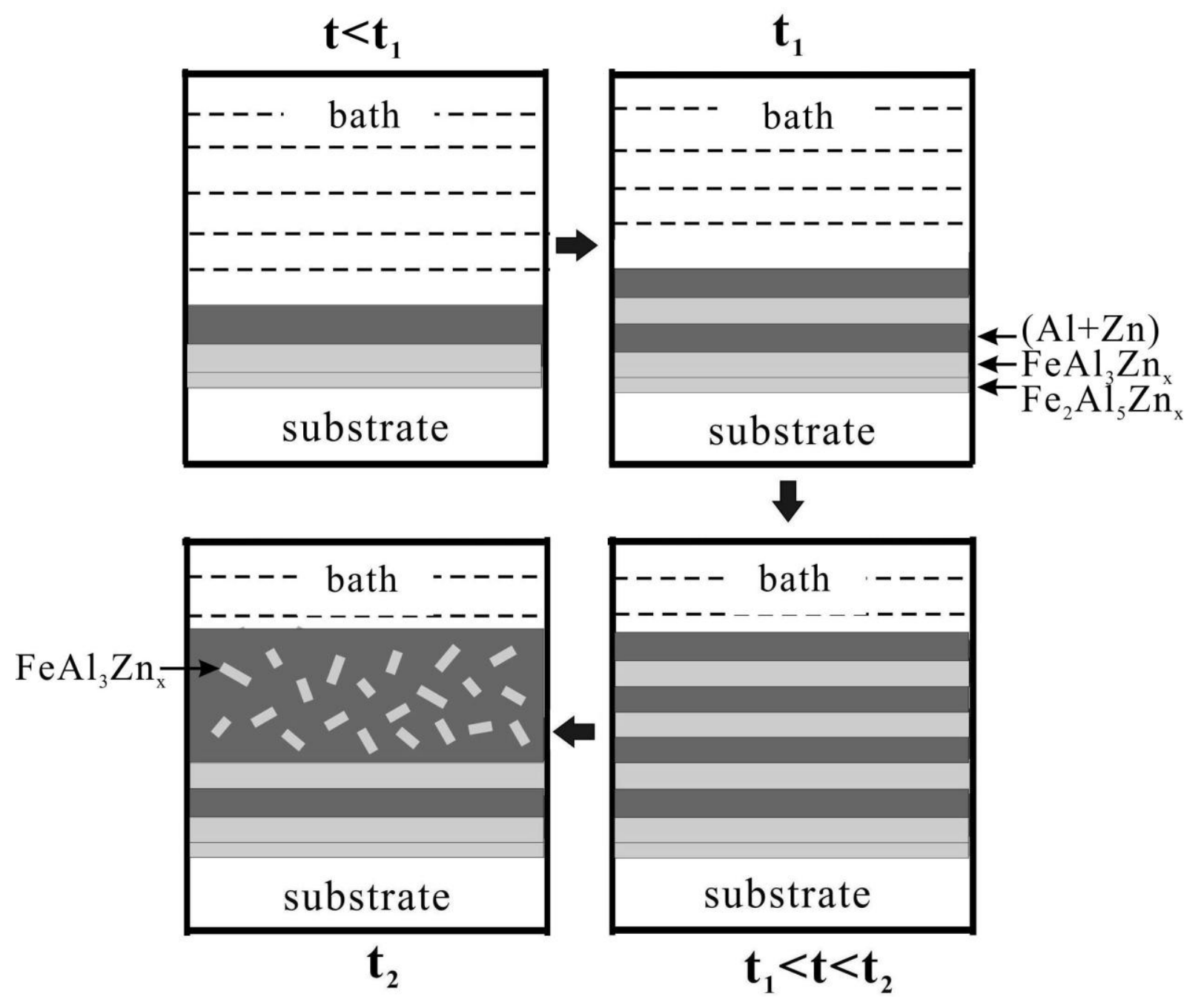




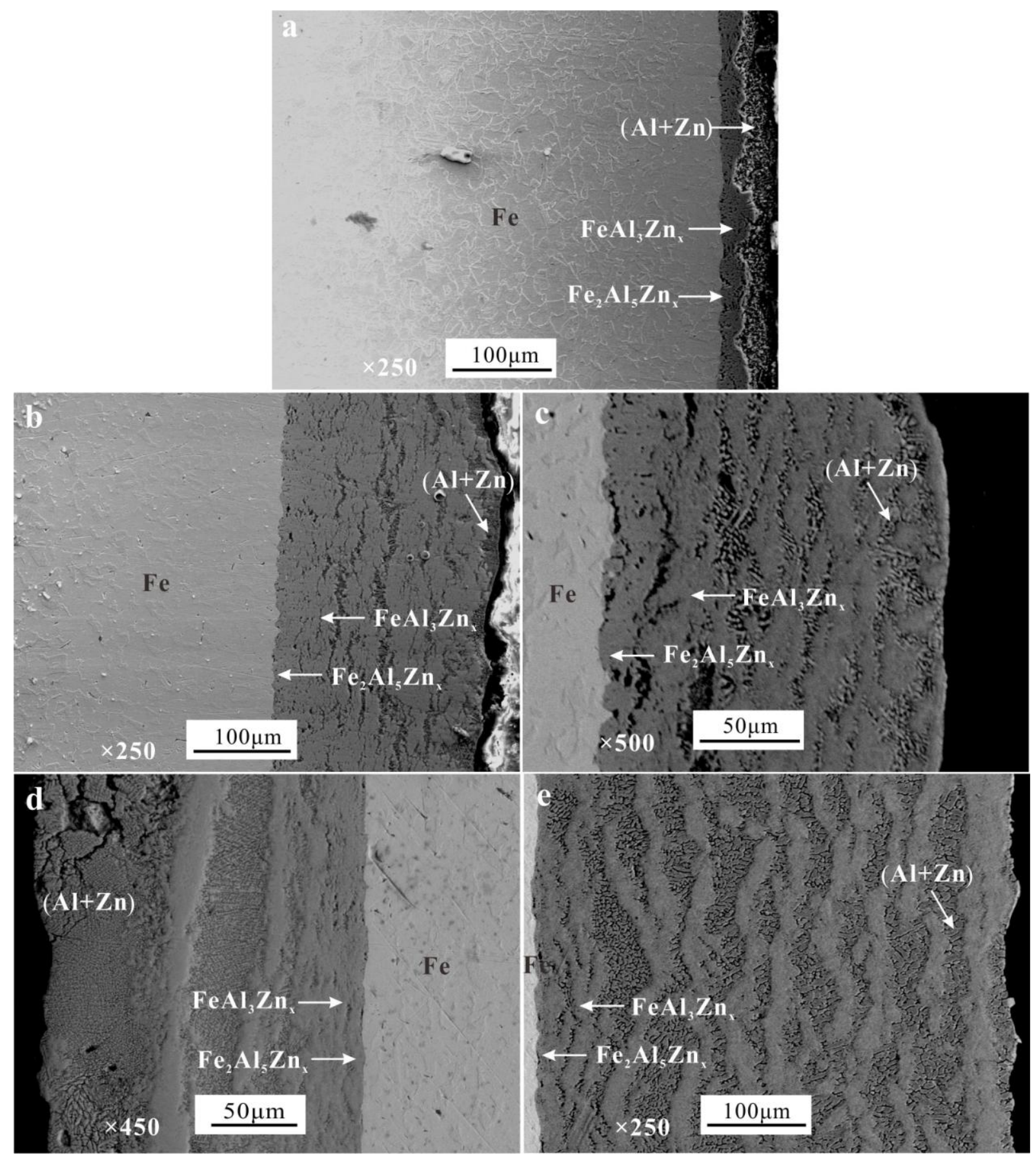



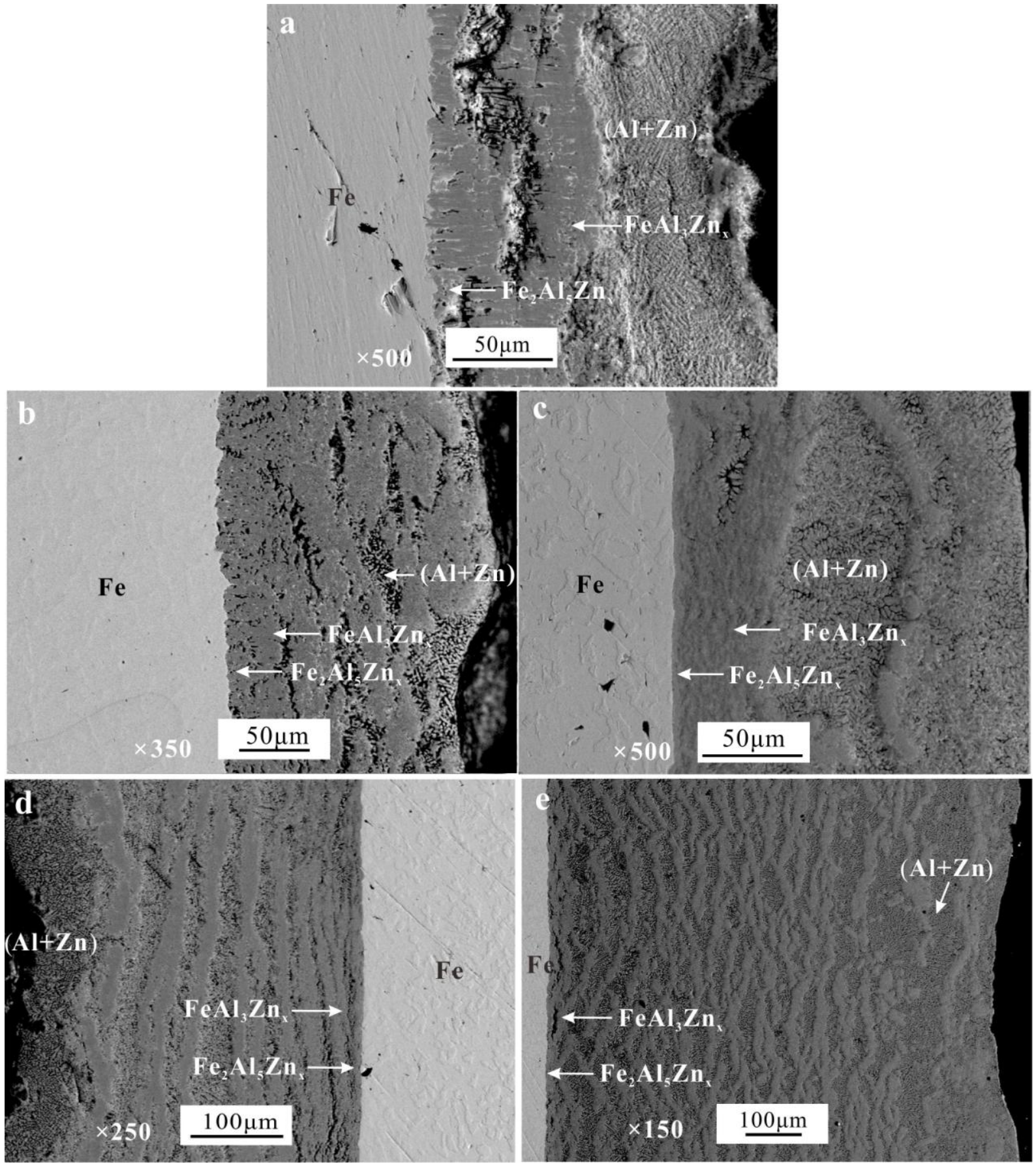


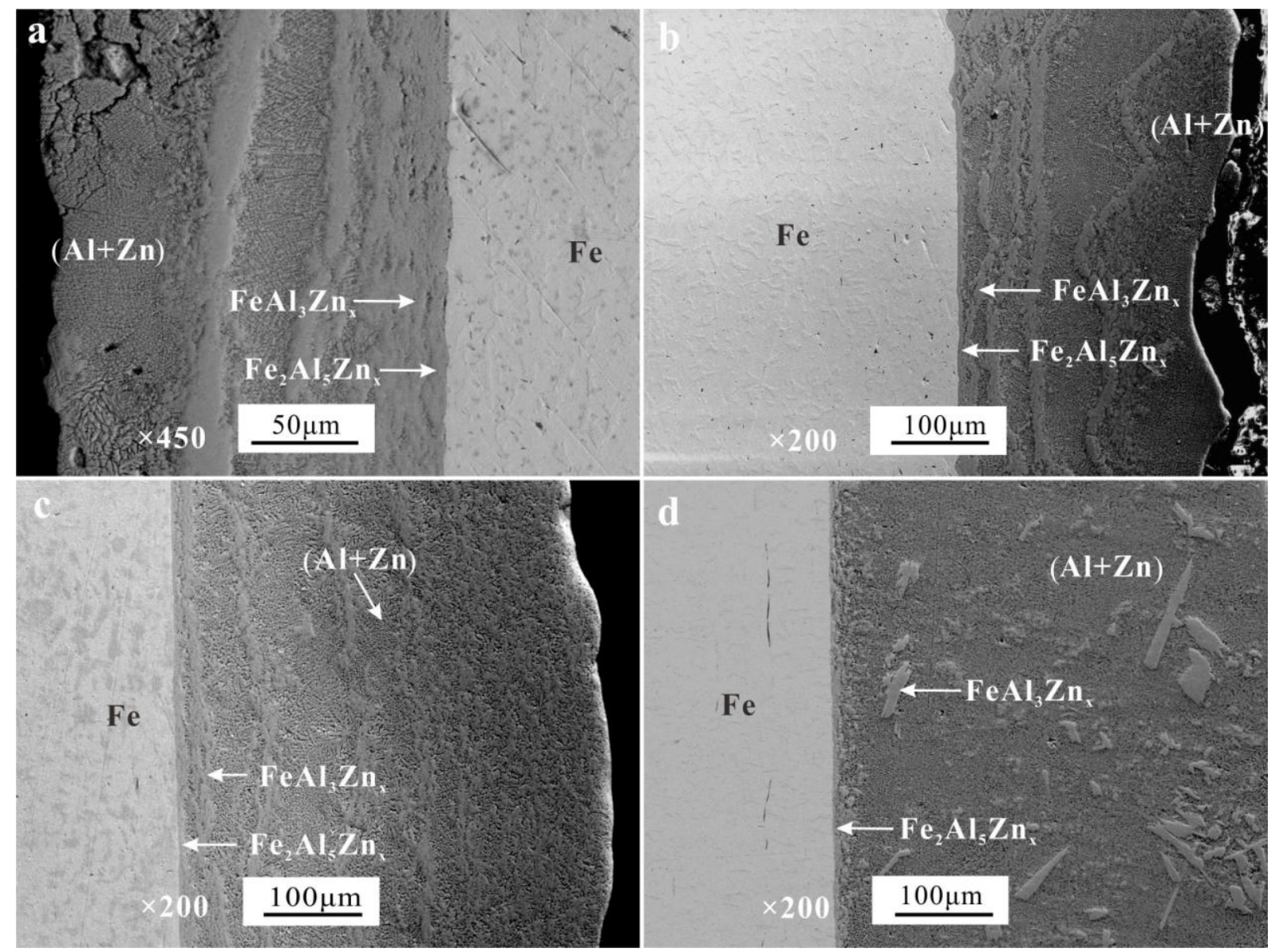




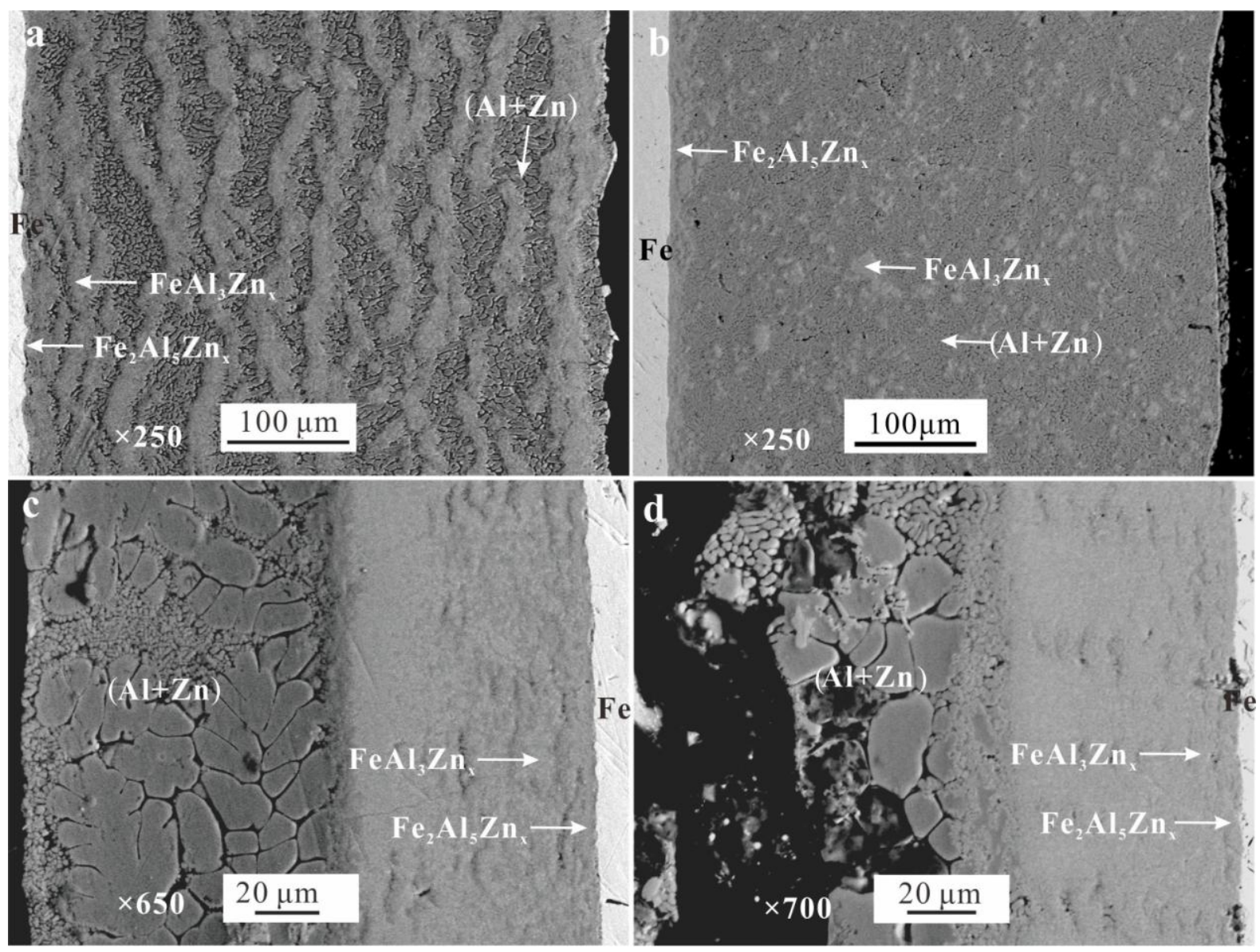


Table 1: Composition of base steel

\begin{tabular}{ccccc}
\hline Element & C & Mn & Si & S \\
\hline Composition (wt.\%) & $0.12 \%-0.20 \%$ & $0.30 \%-0.70 \%$ & $0.20 \%-0.30 \%$ & $<0.045 \%$ \\
\hline
\end{tabular}


Table 2: Composition of baths and corresponding immersion temperature

\begin{tabular}{|c|c|c|c|}
\hline bath & $\mathrm{Al}(\mathrm{wt} . \%)$ & $\operatorname{Mg}($ wt.\%) & Temperature $\left({ }^{\circ} \mathrm{C}\right)$ \\
\hline 1 & 15 & 0.5 & 530 \\
\hline 2 & 15 & 1.5 & 530 \\
\hline 3 & 15 & 2.5 & 530 \\
\hline 4 & 15 & 3.0 & 530 \\
\hline 5 & 25 & 0.5 & 550 \\
\hline 6 & 25 & 1.5 & 550 \\
\hline 7 & 25 & 2.5 & 550 \\
\hline 8 & 25 & 3.0 & 550 \\
\hline 9 & 35 & 0.5 & 570 \\
\hline 10 & 35 & 1.5 & 570 \\
\hline 11 & 35 & 2.5 & 570 \\
\hline 12 & 35 & 3.0 & 570 \\
\hline 13 & 45 & 0.5 & 590 \\
\hline 14 & 45 & 1.5 & 590 \\
\hline 15 & 45 & 2.5 & 590 \\
\hline 16 & 45 & 3.0 & 590 \\
\hline 17 & 55 & 0.5 & 610 \\
\hline 18 & 55 & 1.5 & 610 \\
\hline 19 & 55 & 2.5 & 610 \\
\hline 20 & 55 & 3.0 & 610 \\
\hline
\end{tabular}


Table 3:Composition of flux

\begin{tabular}{ccccccc}
\hline Compound & $\mathrm{ZnCl}_{2}$ & $\mathrm{NaCl}$ & $\mathrm{SnCl}_{2}$ & $\mathrm{KCl}$ & $\mathrm{K}_{2} \mathrm{ZrF}_{6}$ & $\mathrm{CaCl}_{2}$ \\
\hline Composition(g/50ml) & 15 & 1.2 & 4 & 0.5 & 1.2 & 0.6 \\
\hline
\end{tabular}

